\title{
Representación de la violencia y la marginalidad en el discurso de Cidade de Deus e Inferno
}

Matías Rebolledo Dujisin ${ }^{1}$

\section{El problema}

La marginalidad y los discursos que la refieren ocupan un lugar central en la reflexión en torno a América Latina, particularmente desde la rápida, generalmente caótica y siempre segregadora urbanización y modernización del continente desde los años 60 en adelante. Distintas disciplinas han abordado el problema desde perspectivas que muchas veces resultan ser antinómicas; a fin de cuentas, pareciera ser que los problemas de la marginalidad y la violencia dependen (ideológicamente) de los discursos que los enuncian. Esta misma imposibilidad de 'decir' (explicar, dar sentido a) la marginalidad y la violencia urbanas y su evidente impacto social y cultural, sobre todo en las grandes urbes, ha llevado a que el problema sea un tema privilegiado en la producción estética a partir de las últimas décadas del siglo recién pasado, siendo el caso de Brasil paradigmático en este sentido (que se ha convertido casi en un producto de exportación cinematográfico), como la contracara del llamado "milagro económico" y la violencia política de la dictadura militar -particularmente desde el AI-5 en adelante-, con un claro auge en las últimas décadas, gracias a la explosión del crimen organizado en las favelas. La evidente imposibilidad de dar una explicación y un sentido a este panorama de modernización desbocada y mal resuelta, de violencia y desencanto, que sistemáticamente se excluye del discurso hegemónico, se traducen en esta búsqueda estética de comprender, representar, resimbolizar esta realidad cotidiana que no acaba de tener un claro sentido (menos una solución).

De este modo, las novelas y filmes que se escriben actualmente rara vez se configuran como un discurso panfletario o con una 'solución' política. Se puede decir que estas obras están 'más acá': son una búsqueda, una pregunta, no una respuesta. Lógicamente, la búsqueda requiere de una renovación de las formas, explorando miradas alternativas sobre lo real, entendiendo que el realismo es un concepto

1 Doctor en literatura y académico de la Universidad de Chile, Santiago, Chile. E-mail: majorebo@gmail.com. 
inestable, que necesita de constante renovación. Es significativo, en este sentido, que en la producción artística de las últimas décadas, particularmente en Brasil, sea posible observar una tendencia general de regreso a modos realistas de representación, luego de un largo periodo que podría describirse como de "crisis de la representación". Estas nuevas tendencias, prototípicas de épocas de crisis (o post crisis), se caracterizan particularmente por su heterogeneidad y experimentación formal, pero una de las marcas significativas de unidad que podemos encontrar en estas nuevas narrativas es su compromiso explícito con la realidad, pero cuestionando desde su misma enunciación los modos tradicionales de representación e, incluso, lo que se entiende por real (o sus límites con la ficción). De ahí que los narradores actuales, en general, han dejado de posicionarse como testigos privilegiados $\mathrm{y}$ narradores selectos en la directriz de cierta ideología, como podía caracterizarse a la novela realista tradicional, y particularmente desde su lectura latinoamericana. En estas nuevas búsquedas, estos narradores se sitúan dentro de la problemática, pero no para resolverla, sino para mostrar, atestar, evidenciar. Incluso, se puede decir, el acto estético rupturista es una marca ideológica en estos discursos. ${ }^{2}$

Bajo este contexto, en este artículo se analizan dos novelas que abordan una problemática similar, prácticamente contemporáneas, y con amplio reconocimiento y difusión: Cidade de Deus (1997) de Paulo Lins e Inferno (2000) de Patrícia Melo. El objetivo es analizar algunas de las estructuras intraliterarias para, de este modo, intentar demostrar que en su misma construcción verbal estos discursos sustentan una visión de mundo y una concepción ideológica radicalmente distintas, pese a su aparente afinidad, lo que, a su vez, se convierte en un espejo poético de los problemas que enfrentan los discursos factuales (sociológicos, políticos, culturales, históricos) para desentrañar esta problemática. Considerando que es el lugar de enunciación el que construye ideológicamente el discurso sobre la marginalidad, aquí se pretende evidenciar la visión ideológica sobre la problemática que se evidencia en ambos textos en tanto construcción discursiva, mediante un análisis a partir de dimensiones puramente textuales, que, a su vez, nos pueden llevar a consideraciones extratextuales igualmente válidas (sujeto

\footnotetext{
${ }^{2}$ Ver, sobre todo, Scholhammer (2009); también Margato y Cordeiro (2012) y el número especial del Boletin del Centro de Estudios de Teoría y Crítica Literaria (2005).
} 
escritural, recepción, impacto social), pero que, considero, no deben ser el punto de partida, sino de llegada, de las reflexiones en torno a estos dos objetos literarios. Si pensamos en lo que estas nuevas narrativas están intentando proponer, la textualidad es necesariamente política.

De hecho, es por considerar principalmente las novelas en su contexto que ambas se han estudiado y comentado ampliamente desde su impacto social y la recepción general del público, concentrándose en una de las dimensiones de los textos (su función pragmática), olvidando muchas veces lo que en primera instancia son: dos objetos estéticos. Novelas prácticamente contemporáneas, ambas reconocidas por el público y la crítica, el paralelo entre ambas es algo casi indispensable. De una lectura general se desprenden visiones muy similares al mundo presentado: la ausencia de límites (el 'infierno'), la escalada de violencia, el círculo sin salida, la marginación absoluta en todo orden de cosas: económico, social, derechos y deberes ciudadanos en general. Los sujetos adolescentes de estas novelas deben asumir sus propias leyes, en la medida en que el Estado es incapaz de proveer ese marco social mínimo. ${ }^{3} \mathrm{La}$ imagen negativa pero casi necesaria de esta violencia está por lo tanto presente en ambas novelas. Sin embargo, desde un análisis discursivo-literario más acucioso se vislumbran dos posiciones si no opuestas, al menos divergentes, que trasuntan en visiones de mundo diferentes. ${ }^{4}$

\footnotetext{
${ }^{3}$ Lo que Nitschack (2005) entiende como "sujeto absoluto", que debe crear sus propios marcos legales y sociales de representación, ya que el Estado es incapaz de hacerlo, marginalizados de todos los derechos y deberes generales de la ciudadanía.

${ }^{4}$ Para acotar y precisar el concepto, utilizo aquí 'ideología' de manera amplia, no solo como el sistema de ideas y de cognición social que caracteriza a un grupo determinado de manera explícita, o la representación de la realidad propia de una clase social. Siguiendo fundamentalmente a Van Dijk (2008), entiendo ideología como sistemas básicos de cognición social, elementos organizadores de actitudes y de otros tipos de representaciones sociales compartidas por los miembros pertenecientes a un grupo (y no necesariamente de manera absolutamente consciente); en este sentido (y fundamentalmente para este trabajo), las ideologías controlan, de manera indirecta, los modelos representacionales mentales que están en la base y que conforman el contexto introducido en el discurso y en sus estructuras. Es éste el plano ideológico que pretendo describir en las novelas: "las proposiciones [de un discurso] se construyen a partir de modelos mentales como una función de la posición (contextualizada) del lenguaje del usuario, y posiblemente como una función de creencias controladas ideológicamente. Tal perspectiva controla la representación proposicional del espacio y el movimiento, la dirección, la importancia, lo destacable y otros aspectos del significado" (p. 222). Cf. también Eagleton (1997).
} 


\section{La narración}

Un elemento ampliamente destacado por la crítica de Cidade de Deus es su carácter testimonial, lo que la dota de un fuerte contenido de 'realidad'. De hecho, esta primera novela de Paulo Lins fue el resultado indirecto de una investigación sociológica en la que participó como asesor durante unos siete años (1986-1993), como testigo privilegiado de un lugar y un conflicto: residente de la favela de toda su vida, el autor es, además, uno de los pocos que logró tener una educación formal y entrar a la universidad, además de escribir desde su juventud (sobre todo poesía y letras de samba). Fruto de todo eso es esta novela, que cuenta de manera algo fragmentada y caótica, pero macroestructuralmente cronológica, la historia del conjunto habitacional Cidade de Deus, ${ }^{5}$ desde los años 60 hasta su transformación en lo que el mismo Lins llamó "neofavela" (para distinguir esta favela finisecular totalmente caótica y dominada por el narcotráfico de la antigua favela, de las ruedas de samba y el malandragem), que culmina en la guerra de traficantes que ocupa toda la tercera parte del libro. Se compone de tres partes ("La historia de Inferninho", "La historia de Pardalzinho" y "La historia de Zé Miúdo", en la traducción al español), ${ }^{6}$ que, a su vez, representan tres décadas diferentes y tres tipos de criminalidad distinta, lo que le da un cierto orden a una novela que en su estilo se caracteriza por su libertad narrativa, fragmentación y aparente desorganización; va creando, a través de un ritmo frenético, con mucho diálogo (a veces incomprensible), implícitas referencias literarias, la historia de una de las favelas más estigmatizadas de Rio, y una guerra de dimensiones inusitadas, hasta ese

\footnotetext{
${ }^{5}$ Efectivamente, a diferencia de otras favelas, Cidade de Deus fue un proyecto organizado, llevado a cabo por el Estado de Río de Janeiro, como parte de un proyecto de restructuración de la ciudad y la erradicación y reubicación de ciertas favelas, tras un periodo de crecimiento desbocado, y una fuerte reorganización producto de la creación de Brasilia. En 1965 comenzó el proyecto; sin embargo, en 1966, cuando aún estaba a medias, tuvo que ser ocupado de emergencia, por las lluvias y crecidas de ríos que arrasaron con las casas de muchos favelados. Lo que comienza, entonces, como un proyecto gubernamental de reubicación se convierte rápidamente en la "neofavela" que existe hasta hoy.

${ }^{6}$ En una decisión que aún no me explico, todos los nombres de los personajes fueron cambiados en la versión en español (lo que dificulta sobremanera el trabajo comparativo), sin ninguna razón ni lógica aparente, como sería, por ejemplo, traducir literalmente el apodo de un personaje al español (Cabeleira por Cabellera, en vez de "Inferninho"); a veces, todo lo contrario: Zé Pequeno, perfectamente comprensible en español, se convierte en "Zé Miúdo", que quiere decir casi lo mismo en portugués, pero que no denota nada en español.
} 
entonces. De este modo es, sin duda, una novela testimonial y, como resultado de una investigación universitaria, es documento; pero también es una novela 'muy' literaria, con una estructura compleja, que es determinante para los posibles sentidos de ésta.

Una de las cosas que caracteriza la narración de Cidade de Deus es su fragmentariedad y su falta de homogeneidad. A veces presenta rasgos de omnisciencia, aunque sean solo pequeñas infracciones o licencias que se permite. La verdad, corresponde más bien a un caso extremo de focalización variable, ${ }^{7}$ en tanto el narrador se pasea por la conciencia de distintos personajes, pero nunca es realmente capaz de establecer los nexos entre los diversos niveles del relato. ${ }^{8}$ La mayor parte del tiempo el narrador solo sabe fragmentos de historias, cuya selección, ordenación y presentación parece a veces simplemente aleatoria, dejando en general que los personajes dialoguen libremente, sin necesariamente introducir el contexto de la discusión (como una cámara errática que azarosamente descubriese una conversación). No parece haber un claro hilo conductor entre un fragmento y otro. Algunas historias quedan abiertas (la mayoría) y muchas se resuelven con alguna mención marginal. Por contrapartida, de vez en cuando, sobre todo en la apertura de la novela, aparece una voz que está 'más acá' que la voz del narrador, mostrando una clara consciencia autorial, metaliteraria, pero que no logra dar una cohesión suficiente al texto: "Poesia, minha tia, ilumine as certezas dos homens e os tons de minhas palavras. É que arrisco a prosa mesmo com balas atravessando os fonemas. É o verbo, aquele que é maior que o seu tamanho, que diz, faz e acontece. Aqui ele cambaleia baleado [...] Falha a fala. Fala a bala" (Lins, 1997, p. 12). ${ }^{9}$

\footnotetext{
${ }^{7}$ Los conceptos usados para el análisis estructural de estas dos novelas se basan fundamentalmente en la propuesta de Gerard Genette en "Discurso del Relato", ampliamente difundidos. Por esta razón no se explicará cada concepto narratológico utilizado.

${ }^{8}$ Pasa de la descripción de estados internos de los personajes, como: "Marreco saiu de perto dos amigos, pensou em entrar no banheiro, mas preferiu ir para fora da casa. Uma tristeza acompanhava seus passos, não escutava mais o que os amigos diziam [...] Olhou para o céu, depois para o chão, concluiu que Deus ficava muito longe [...] Se o inferno é embaixo da terra ele está muito mais próximo" (Lins, 1997, p. 17), a desconocer incluso los nombres de los personajes que participan: "un hombre", "el de allá", "la de Ceará", etc.

${ }^{9}$ De vez en cuando esta voz 'poética' vuelve a aparecer, a lo largo del relato: tras la muerte de Salgueirinho: "Deu-se um corte na manhã, oriundo de uma oração de verbo intransitivo e sujeito morto. As ruas ficaram cheias de choro pelas esquinas" (Lins, 1997, p. 101). O "Matar, matar, matar...Verbo transitivo exigindo objeto direto ensanguentado" (p. 211).
} 
En cambio, Inferno presenta un claro narrador omnisciente o de focalización cero. La novela relata una historia mucho más simple, en términos argumentales. Cuenta la historia de José Luís, Reizinho, de manera bastante lineal, desde que éste es niño y sueña con ser traficante y líder de la favela, paso a paso, hasta que consigue su objetivo, lo que implica necesariamente una serie de traiciones (a sus amigos, a su familia y a sí mismo) y el constante peligro de ser derrocado, lo que eventualmente acontece hacia el final de la novela, implicando la necesaria fuga del protagonista y su eventual cambio de vida. Sin embargo, la novela termina con el personaje regresando a la favela y dejando el único cabo sin atar: ¿qué sucederá con José Luís?

Como podrá apreciar todo lector de la novela, más que la historia de Reizinho como sujeto individual, es una historia ejemplar (lo que se hace evidente desde el título) en torno a la vida en la favela y el mundo del narcotráfico. Reizinho es uno más de tantos niños con sueños de poder dentro de su estrecho mundo, y es uno de los pocos que lo consigue. De ahí que, a juicio mío, la presencia del narrador no focalizado sea fundamental, evitando la tendencia hacia lo excesivamente individual de esta historia, que asume un carácter ejemplar. ${ }^{10}$ Como todo narrador omnisciente a ratos adopta un punto de vista o focalización fija en alguno de sus personajes (sobre todo en su protagonista), cambia a una mirada externa, sin que ello implique un cambio de voz: el narrador es siempre el mismo, utilizando todas las estrategias tradicionales del relato no focalizado, y dando una apariencia de cercanía gracias a un uso profuso del indirecto libre (técnica que fue introducida con gran maestría por los autores de uno la novela realista tradicional, particularmente Flaubert). Un ejemplo cualquiera. Casi todos los capítulos comienzan con descripciones caóticas de los espacios; éste es el principio del segundo capítulo:

Pavão Pavãozinho, metralhadoras, escopeta e granadas, trinta homens. Ladeira dos Abacantes, quarenta homens, fuzis AR-15 e HK-47.

\footnotetext{
${ }^{10}$ Hago referencias a algunos teóricos clásicos del realismo, en la medida en que ambas novelas se inscriben explícitamente en esta tendencia, al intentar reproducir, reflejar o construir un mundo literario, equiparable al real. Pero los modos del realismo es ambas son disímiles, según la tendencia actual antes descrita; es parte de lo que se quiere demostrar acá. La referencia directa en este caso es Lukács, que sitúa la materia del realismo en lo particular: ni en lo universal, fuera de todo contexto, ni en lo individual, desconectado de las fuerzas históricas que lo determinan. Exceptuando por su estilo, es posible, de hecho, una identificación casi directa de las características de esta novela con las propuestas por este teórico, sobre la novela realista decimonónica.
} 
Morro da Maria Penha, líder Creudão, cinquenta homens, armamento importado. Morro da Baiana, noventa homens, pistolas, escopetas, líder Feinho [...] Reizinho, na cada de Bidê, o secretário geral da boca-de-fumo do morro Berimbau, aguardava ser atendido. Gostava de memorizar os nomes das favelas, com seus líderes e suas armas" (Melo, 2000, p. 18).

En este último párrafo se puede notar que lo que aparece en voz del narrador como una aparente enumeración caótica en realidad corresponde a lo que en términos generales (y no necesariamente con las exactas palabras) a los pensamientos de Reizinho mientras espera sentado. Discurso que supuestamente correspondería al personaje, pero en la voz del narrador: ejemplar del indirecto libre. Casi todo el texto está escrito de esta manera, creando un ritmo rápido, cercano, que transita entre la descripción externa, los diálogos o pensamientos de personajes, en voz del mismo narrador, y algunas explicaciones causales propias del narrador omnisciente. De esta manera, pese al grado de acercamiento empático que implica el uso de esta técnica narrativa, la visión del narrador se mantiene siempre 'desde arriba', ordenando, estructurando, dando una cohesión y una coherencia al mundo presentado. El narrador comenta y juzga, aunque sea de manera implícita (guiando el juicio del lector), los hechos de la novela; sabe las verdaderas razones de los actos o lo que realmente ocurrió en tal o cual momento, y de este modo desembrolla y da sentido (causal y racional) a los actos que presenta la novela. ${ }^{11}$ Como señala el crítico Adélcio de Souza Cruz (2010, p. 4), “O elemento que não posso deixar de mencionar complementa a classe da voz narrativa: onisciência. Isso reforça, ainda mais, a 'naturalização' das diferenças sociais como algo irreversível e/ou imutável". Así, su enunciación necesariamente guía o encauza la lectura hacia una mirada más o menos unívoca, lo que ideológicamente manifiesta una construcción ordenadora de mundo, monológica, y unívoca en su interpretación, connotando, además, como señala el crítico citado, una naturalización del mundo presentado. Esta

\footnotetext{
${ }^{11}$ Ejemplar en este sentido es la muerte del mejor amigo del protagonista, Leitor, descrito en el último capítulo de la novela, que es el que, además, hace más explícita la función ideológica del narrador: "Embora muita gente teimasse em dizer que a morte de Leitor fora obra do Volnei, $a$ verdade é que ele falecera num incêndio provocado por uma vela deixada em seu barraco pelo amigo Onofre [...] Ao contrario do que os amigos imaginara, o seu fim não foi um momento de terror, mas de paz e alívio" (Melo, 2000, p. 361-362; el subrayado es mío). Cual Balzac, el narrador no se permite dejar cabos sueltos, no quiere la ambigüedad interpretativa y, así, todo lo que puede ser explicado, es explicado (y, a veces, juzgado).
} 
es, de hecho, una de las críticas más drásticas desde el postmodernismo, particularmente Lyotard (2012), a la novela realista, señalando que en la práctica se caracteriza por su conservadurismo estético e ideológico, que aspira a un (re)conocimiento de mundo que supone certezas morales, totalidad, coherencia experiencial. Ese 'engaño ideológico' se logra precisamente adoptando formas simples que le permiten al lector reafirmar una interpretación predecible y unitaria del mundo, que evidentemente no se corresponde con el universo social del capitalismo tardío. Contra argumentando a la vez que apoyando la tesis de Lyotard, no hay que olvidar que la novela realista produjo, en sus orígenes, todo lo contrario: técnicas y temáticas rupturistas que desacomodaban al lector (burgués), creando una mirada distanciada y crítica, a la vez que cercana, de su mundo cotidiano. Pero en su defensa habría que decir que esas mismas técnicas han establecido un cierto paradigma de la novela que efectivamente produce, hoy, esa conformidad lectora, ese reconocimiento de formas naturalizadas que nos acercan más a lo literario que a la realidad que se pretende representar.

La voz narrativa en Cidade de Deus intenta crear un discurso opuesto al anterior. Con su 'invocación' a la poesía muestra estar consciente de las dificultades, de la imposibilidad de verbalizar esta historia, de darle una coherencia discursiva. La falta de articulación entre una secuencia narrativa y otra, y la clara fragmentariedad de éstas, unidos a este narrador generalmente parco y distante, que evita explicaciones $\mathrm{y}$ causalidades, expresan discursivamente la falta de asidero de la realidad que se quiere representar, un mundo del que el narrador forma parte pero que capta solo de manera parcial, inconexa $\mathrm{y}$, a veces, subjetiva. Hay una suerte de mirada oblicua que remarca tanto la importancia de la percepción en la configuración de lo real (y de este modo la imposibilidad de un orden absoluto), mientras se explicita la dificultad de esta misma percepción en la realidad presentada. Si hay que ligar este estilo narrativo con una tradición del realismo, me atrevería a vincularlo con un realismo social del siglo XX latinoamericano post-naturalismo y criollismo, cuyos casos ejemplares me parecen Juan Rulfo (incluyendo Pedro Páramo, pese al carácter 'mágico' que se le ha adosado a su realismo) y en Brasil, Graciliano Ramos, sobre todo en Vidas Secas (por la fragmentariedad y subjetividad de la realidad percibida; la imposibilidad de la totalidad perceptual y la explicación unívoca de esta realidad). Sin embargo, este es un narrador 
que va un poco más allá, evidenciando el carácter poético de su creación. Con esta 'invocación' (situada justo cuando va a comenzar a contar la historia) manifiesta que 'quiere pero no puede' saber, como un vate antiguo imposibilitado de visión, cuya únicas certezas son lo que ha visto y las palabras que utiliza, pero no la relación entre un nivel y otro, que se le escapa.

En cambio, la voz de la novela de Melo sabe, y quiere contar. Ordena y da sentido al mundo. En ese sentido, Inferno es una novela con claras pretensiones de totalidad, linealidad y causalidad, más cercana a la tradición de la novela naturalista, en cierta medida. A veces la narración juega con la apariencia de caos, de desprolijidad, como en casi todos los principios de capítulo, donde se describe el espacio a través de la enumeración caótica: "Sol, piolhos, trambiques, gente boa, trapos, moscas, televisão, agiotas, sol [...] Subindo. Ruas de terra batida. Onze anos, o garoto, Reizinho. Pipa nas mãos. Pés descalços" (Melo, 2000, p. 9). Pero es una descripción focalizada e intencionada (el desorden del mundo se mimetiza con el desorden verbal). También aparecen algunos vacíos en la historia central, pero estos prontamente son llenados por el narrador. Es la clásica forma del suspenso narrativo, con analepsis que llenan a posteriori lagunas del relato, enfatizando una estructura totalizante.

\section{Estructura de la historia y configuración de personajes}

En cuanto a la estructuración de la historia, en Lins ya veíamos una progresión algo convulsa, a través de los capítulos, de un cierto tipo de violencia, dirigida y controlada, hacia una violencia generalizada y absoluta, que domina la favela completa. Pero en ningún caso se trata de una historia lineal, con un principio medio y fin aristotélico. Es, de hecho, en estricto rigor, una "obra abierta": la serie de hechos fragmentarios y discontinuos, y la cantidad de personajes esporádicos, podría haberse aumentado ad infinitum, aglutinados o no en torno a los hechos principales, fundamentalmente la guerra. ${ }^{12}$ Sin embargo no es

\footnotetext{
${ }^{12}$ Con el contraste con la fábula aristotélica me refiero al dictum del Estagirita, que sigue dominando aún en la narrativa más tradicional, de que nada puede ser sacado y nada añadido para que la obra sea perfecta. Es decir, un entramado perfecto de hechos, concatenados lógicocausalmente (y no temporalmente). En contraste, los fragmentos de Cidade de Deus pueden ser suprimidos, modificados, alternados, sin que esto signifique una desarticulación de la novela (vale en este sentido también la relación con Vidas Secas). Vale la pena citar, como anécdota, lo que el mismo autor dice sobre su novela: luego de años trabajando en un texto que parecía infinito, su
} 
sobre estos personajes ni sobre la guerra esta novela. La guerra es la conclusión inevitable de un espacio condicionado para ésta.

El contraste con la novela de Melo es evidente e inevitable. Nuevamente aquí nos podemos encontrar con una cierta incongruencia entre un estilo en apariencia desprolijo, con una historia perfectamente construida, cronológica y causalmente, en torno a un solo proyecto central, el de Reizinho, más algunas historias secundarias, que le dan vida a una novela ricamente construida, y que intenta ser una novela de espacio, pero que, más bien, se configura como una novela centrada fundamentalmente en un personaje. Es, de hecho, esta conjunción (el personaje individual central y el espacio que pretende ser la condicionante absoluta, dentro del texto y fuera de él), la que da forma a la tendencia ejemplar y moralizante de la novela.

Podemos seguir esta misma directriz de la historia en la caracterización de personajes, que se van construyendo de manera similar. En términos muy gruesos, como hemos visto, ambas se inscriben dentro de la tradición realista, aunque con distintos enfoques. En la historia de la novela realista el personaje siempre ha ocupado un lugar privilegiado en la construcción argumental y del sentido textual (frente al privilegio de la fábula aristotélica, por ejemplo); es el lugar donde confluyen tanto las dimensiones individuales como las determinaciones históricas, además de producir la posible identificación con el lector. ${ }^{13}$ Bajo este punto de vista, Cidade de Deus se contrapone a las determinaciones fundamentales del personaje realista, puesto que la estructura fragmentaria y errática del texto impide el desarrollo pleno (psicológico, causal) de los personajes, incluso los principales (con la casi exclusiva salvedad de Zé Pequeno y Bené). La novela se empeña en evitar la exposición de la psicología profunda y se queda en una simple mostración de acciones y diálogos, a veces sueltos y sin continuidad. Es un panorama de personajes inconclusos. En ese sentido sería anti-

psiquiatra le preguntó qué es lo que no lo dejaba salir adelante; Lins respondió: "la novela"; el doctor le dijo entonces que la terminara. Ese día le puso punto final, donde había quedado. Luego, el editor le diría que estaba demasiado larga para venderse. El novelista dejó que el editor cortara 300 páginas para dejarla en la forma que tiene actualmente. Así de poco orgánica sería esta novela (si creemos en las palabras del autor) desde su misma génesis.

13 Ver fundamentalmente Lukács, para quien la creación de tipos sería uno de los objetivos centrales del realismo literario. También el tratamiento que hace Auerbach de los personajes en Mimesis. El naturalismo se define desde Zola como el "estudio de las pasiones", esto es, de sujetos individuales puestos en situaciones particulares; etc. 
luckacsiana, puesto que donde confluirían las fuerzas históricas sería más bien en el espacio mismo, y es ese espacio el que permite el surgimiento de los personajes, pero sin caer en el determinismo. En Cidade de Deus, como en otras novelas que abordan problemáticas similares desde una visión crítica (pensemos en Ferréz, por ejemplo), tenemos individuos que no se logran configurar plenamente como sujetos, dado que el contexto social e histórico en que se ven inmersos impide el desarrollo de dicha subjetividad, marcada por la identidad individual y los valores sociales de la familia, el trabajo y la amistad, amparado en un contexto de ciudadanía provisto por el Estado. Ante el fracaso de esta configuración, los sujetos se ven desprovistos de una subjetividad que los identifique, o bien dicha subjetividad se fragmenta entre los retazos de personajes que la novela presenta. Esto no es sino, a nivel textual, una crítica al macro discurso moderno de la ciudadanía y el Estado, que muestra su fracaso en la novela.

En Inferno, en cambio, pese a la relevante presentación del espacio (prácticamente todo ocurre en la favela) y la estructura de la acción, la novela se configura en torno a un protagonista claro, y cada personaje, por muy secundario que sea, tiene su historia, su lugar en ese mundo. Como señalaba anteriormente, es Reizinho quien guía el relato completo. De ahí en más, pese a que cada personaje es ampliamente explicado y desarrollado en profundidad (descripciones, pensamientos, acciones), la novela en general tiende a la tipificación (en un sentido negativo, no lukacsiano), ${ }^{14}$ creando personajes que si bien no son planos (tienen rasgos contradictorios que los identifican), tienden a ser marcadamente estáticos. Caroline con su mundo televisivo, sin ambiciones, su gordura y sus embarazos indeseados; la burguesía ostentosa de Dona Juliana, preocupada por las apariencias y sus jóvenes amantes como único sentido de vida; la siempre humillada y sumisa

\footnotetext{
${ }^{14}$ Recuérdese que la creación de 'tipos' sería el ideal de la novela realista para Lukács, puesto que en éste

"confluyen y se funden todos los momentos determinantes, humana y socialmente esenciales, de un periodo histórico [... El tipo es] la particular síntesis que, tanto en el campo de los caracteres como en el de las situaciones, une orgánicamente lo genérico y lo individual" (Lukács, 1965, p. 13). Ninguna de las dos novelas, pienso, se acercan a este ideal. La novela de Melo, empero, que sí profundiza en sus personajes, tiende al 'tipo' en su uso más común, esto es, personajes que se caracterizan por unos pocos rasgos, y que tienen un rol social definido.
} 
Alzira. ${ }^{15}$ Ningún quiebre en el argumento cambia ni su actuar ni su visión. El último capítulo, que es el que más expresamente se estructura como la fábula moral de la novela, nos muestra que cada uno de estos personajes ha terminado tal como desde un principio se había previsto.

Reizinho es, como personaje central, quien más cambia a lo largo del texto. Pero ese cambio es solo aparente. José Luís tiene un solo proyecto que se mantiene constante a lo largo de todo el texto: ser bandido; tener poder y ser respetado. Como dice Lúcia Zolin (2006, p. 73), “[a] trajetória do protagonista Reizinho é marcada pelo desejo de ascensão no mundo do narcotráfico, que, na verdade, consiste na única possibilidade de transcendência que ele conhece". Esto, de hecho, se formula explícitamente en la novela: "Reizinho, desde pequeno, só possuía um objetivo na vida: ser traficante" (Melo, 2000, p. 147). El relato es el proceso que lleva el proyecto desde la potencia a su cumplimiento, paso a paso ${ }^{16}$. Incluso en el final de la novela, cuando suponemos un quiebre definitivo, volvemos al eterno retorno del infierno. O bien el protagonista regresa como el líder que fue, o bien, mucho más probablemente, muere en su ley. No hay ningún cambio real en él. Solo los pasos necesarios del crecimiento y la obtención del poder. ${ }^{17}$ De este modo los personajes quedan encasillados en un rol tipificado y maniqueo, muy predecibles y cercanos al determinismo (aunque la hábil prosa de Melo logre parcialmente ocultarlo), como

\footnotetext{
${ }^{15}$ Como el mismo narrador señala (aunque siguiendo la perspectiva de Reizinho): "Na favela, os meninos são muito magros e as adolescentes, gordotas. As mulheres são obesas e os homens ventrudos. É a regra" (Melo, 2000, p. 45).

${ }^{16}$ De aquí que sea tan lineal la construcción de la diégesis. Aunque no es el objeto acá, la novela puede ser explicada macroestructuralmente desde un solo esquema actancial, en el modelo de Greimas (con muchas historias secundarias, evidentemente, que le dan "cuerpo" a la historia, y modificaciones en ciertas funciones a lo largo del relato), lo que es una excepción en novelas de cierta extensión y complejidad, para las cuales el modelo suele ser muy insuficiente. En términos del análisis secuencial por proyectos de Brémond, también presentaría una estabilidad inusual para la narrativa contemporánea.

${ }^{17}$ Incluso la novela puede leerse como una novela de (de)formación (o anti-Bildungsroman), en tanto el personaje va gradualmente 'aprendiendo' a ser un mejor bandido, lo que implica necesariamente una degradación en la escala humana, que tiene marcas explícitas en el texto: es descrito en un principio como "un buen niño"; surge luego su deseo de ser traficante, se hace dependiente de la droga, golpea a su madre, roba a su abuela (su único familiar realmente querido), se mete en el narcotráfico, traiciona a su mentor y se hace del poder, asesina a su mejor amigo. Progresión paso a paso propia de la novela naturalista, y en este caso, como planteaba, su aprendizaje-formación (como maleante) se asocia a una degradación explícita en su formación como individuo (ciudadano).
} 
Reizinho, que es el claro producto de un padre alcohólico, ausente, y su humillada madre, que encarna además la violencia cotidiana; así puede ser leído cada personaje. Como contraparte, los personajes de Lins no caen en dicha tipificación, pero esto es porque casi no alanzan siquiera a ser personajes en el propio sentido de la palabra, como la novela realista nos había acostumbrado.

\section{Estilos narrativos}

Por último, quisiera detenerme en algunos elementos propiamente discursivos, como la construcción verbal y el estilo narrativo. La novela de Lins es famosa, entre otras cosas, por el lenguaje utilizado. Como producto indirecto de una investigación sociológica, Lins incorpora los giros lingüístico de la propia favela en la época en que se sitúa. Por eso los diálogos son difíciles de leer incluso para un hablante nativo del portugués. En este sentido son reconocibles tres estilos diferentes: primero, una voz narrativa que se limita a presentar los hechos, sin involucrarse en el relato ${ }^{18}$. Segundo, el habla de los personajes, casi incomprensible. Finalmente, una voz esporádica, que podría asociarse a un posible autor implícito, que revela la dimensión poética y ficcional de la novela, alejándola del mero documento. Es en ese sentido un ejercicio formal y extremo del realismo: el habla de los personajes es indispensable para recrear una realidad que se quiere auténtica, aunque no se entienda (¿se entendería en la vida real? ¿por qué la literatura necesita subtítulos?); también lo es del realismo de la forma: el texto no esconde su dimensión estética y su ficcionalidad. La realidad es tan difícil de asir como el texto.

El discurso de Inferno tiene un estilo en apariencia desprolijo, lleno de descripciones caóticas y un abundante uso del indirecto libre, como vimos anteriormente. Las descripciones apuntan a crear precisamente el

\footnotetext{
${ }^{18}$ Esto es muy evidente en las descripciones de los hechos más impactantes de la novela, que son muchos. El narrador solo describe, no enjuicia, en un lenguaje directo y detallado, actos como la mutilación de un bebé por venganza, violaciones, asesinatos terribles, etc. Aquí, un ejemplo cualquiera: "Fritas caiu desmaiado, Biscoitinho pediu o fuzil a Pequeno, colocou o cano dentro da boca do menino e disparou oito vezes, movimentando em círculo o cano do fuzil para ele nunca mais xingar a sua mãe [...] O corpo do menino era somente um amontoado de sangue [...] Um pedaço da cabeça num lado da viela, um dos olhos solto, intato, como se estivesse olhando para ele, pequenos pedaços ensangüentados espalhados, e somente a parte de baixo do rosto presa ao pescoço (Lins, 1997, p. 411-412).
} 
ambiente a su vez caótico de la favela; el ritmo del lenguaje quiere mimetizar el mundo que describe. Inevitablemente, sin embargo, el discurso tiende al lugar común y al prejuicio. Por su parte, el indirecto libre intenta por un lado asimilarse al habla de los personajes y por otro, adoptar una mirada aparentemente cercana, desde la óptica de estos: "Ploc, ploc, ploc, ela fazia bolas enormes com goma de mascar, uma atrás da outra, com muita rapidez. Ninguém é melhor nisso que eu, dissera a garota, ploc, e era verdade, porra" (Melo, 2000, p. 227). La verdad, ninguna de las dos cosas ocurre realmente. Primero, en ningún momento el discurso narrativo se asimila al habla de los personajes; quiere hacerlo, con estructuras sintácticas simples y breves, interjecciones ('porra') y onomatopeyas pertenecientes a su discurso ('ploc, ploc, ploc'), y mucha yuxtaposición frástica. Sin embargo, nunca se pierde de vista que es el narrador el que habla, que quiere 'hablar por' sus personajes. Pero la selección léxica (exceptuando el uso casi exclusivo del 'porra'), el tipo de frases y argumentos, son evidentemente de un discurso oral culto. Por ejemplo, el narrador se empeña en remarcar que ninguno de los traficantes es capaz de comprender palabras como 'hebreu', 'primogénito', o 'Haiti'. ¿Podría, entonces, José Luís describir su sensación con el crack como "algo esburacado no seu peito, um buraco enorme, vários, e ausências, uma tristeza difusa" (p. 55)?

Claramente hay una transición entre en lenguaje coloquial-favelado a un lenguaje poético, del narrador; pero tal transición no hace sino reforzar el prejuicio (ningún habitante de la favela entiende bien lo que habla; no saben más que un par de frases articuladas, etc.). En los casos dudosos, el narrador se empeña en distanciarse de las opiniones de sus personajes, como cuando a José Luís le gustó un filme, "'a pesar de ser preto-e-branco'” (p. 66), único momento en que se cita el discurso de personajes entre comillas (el lector pudiera pensar que es el narrador $-\mathrm{y}$ a través de él la autora- el que descalifica el cine en blanco y negro, y no el ignorante de Reizinho). Esto, junto a la clara omnisciencia narrativa, inevitablemente crea una distancia ficcional inconmensurable entre el narrador y sus personajes, y se hace ostensible, de este modo, su vano intento de mimetizarse entre ellos, de hablar 'desde abajo', cuando claramente presenta una visión 'desde arriba', totalizante, juzgante, dispensadora de mundo. 


\section{Conclusiones}

Inferno, a través de su estilo y técnica narrativas, crea un discurso moral que quiere demostrar una tesis (que parte desde su título): el mundo de la favela es el peor espacio imaginable, el lugar de los excluidos y marginados, que no tienen cabida en la ciudad moderna. Son la lacra, inmersos en una red de violencia de la que no se puede salir, donde los buenos son buenos y los malos, malos, con una clara moral del "crime doesn't pay". Hay un juicio evidente que mira, como en la novela naturalista, ese mundo como en un laboratorio, y otorga la moral explícita en su título. El infierno es esto, este mundo que está a nuestras espaldas, el 'lugar sin límites' del Fausto de Goethe. Si no ha quedado claro, viene el epígrafe (innecesario, a mi juicio, en la medida en que el título evoca inmediatamente un tipo cultural, más allá de Virgilio). ${ }^{19}$ Aun más, si alguien todavía no comprendiese la relación, en varias oportunidades distintos personajes declaran vivir "en un infierno". Claramente, eso sí, el juicio moral no quiere caer sobre los favelados, sino que éstos estos aparecen como los receptores del fracaso del Estado y sus instituciones como garante civil; sin embargo, queda claro, también, que ellos son los que permiten que ese infierno siga existiendo. El título de Cidade de Deus, en cambio, trae consigo, pienso, una doble ironía. Para un brasileño, sobre todo carioca, el título de la novela simplemente hace alusión a un lugar geográfico real donde se sitúa la acción. Pero para un extranjero (por ejemplo), en primera instancia aparece como un nombre simbólico o alegórico, de la misma manera que la novela de Melo, pero en un sentido oscuramente irónico (incluso, tal vez, haciendo alusión al texto de San Agustín). Entonces se produce la doble ironía cuando nos damos cuenta de que el nombre no es una ironía: es real. La doble ironía niega la ironía y nos sitúa con mayor intensidad en el campo de lo real. Los personajes de Patrícia Melo viven en el infierno; los de Lins, en la Cidade de Deus. Literalmente.

De este modo, con los elementos narrativos antes descritos, y varios más que omito, se puede llegar a ciertas lecturas de los textos, que no remiten

\footnotetext{
19 “A descida é fácil, as portas do inferno estão abertas dia e noite” (Vigílio, Eneida, Livro VI). La hipótesis explícita de la novela, que se va probando paso a paso, hasta la conclusión final del último capítulo, que redondea el mensaje moral.
} 
necesariamente al contenido de lo relatado, sino al tratamiento que reciben dichos acontecimientos. Con un estilo muy atractivo y convincente y un manejo muy profesional de las técnicas narrativas, Patrícia Melo crea un relato muy ágil y envolvente, que atrapa desde un principio, y permite seguir los acontecimientos como se sigue una película de acción. Pero el estilo aparentemente cercano, mimético tanto del habla de los favelados como de la realidad caótica de la favela, es solo apariencia. Es a fin de cuentas un discurso altamente conservador, que prefiere la mirada del narrador omnisciente tradicional (que intenta enmascararse en algo que no es), que propone una mirada superior, creando una distancia insalvable entre la voz y su historia, y que tiende a la totalización; un discurso que propone un orden de cosas con una causalidad evidente y con un juicio moral explícito. La 'democracia discursiva' de la novela es, a mi juicio, puramente cosmética. Las estrategias textuales, que se emparentan con las técnicas que usó el realismo tradicional para dar cuenta de la decadencia del mundo burgués y de la primera industria, revelan finalmente, a mi juicio, una mirada distante y que se quiere crítica, pero que termina por legitimar la realidad que expone dándole, tal vez a su pesar, un 'lugar en el mundo', una pertenencia a un cierto orden de cosas. En su intento de totalidad, lo real se escapa.

No está de más señalar que este artículo no pretende ser, a su vez, un juicio valórico sobre la calidad de la novela de Melo, que considero que es buena, ni menos aún sobre su calidad moral o la de su autora. Se pretende desmantelar lo que el discurso propone y lo que éste sostiene como construcción discursiva. Es que el plano ideológico necesariamente viene marcado en discursos que tratan temas tan complejos -en todo discurso, en realidad-, sobre todo en el plano valórico. La simplificación de la historia o su (anti)paralelo con la novela de formación no suponen un juicio a priori, sino un lugar de enunciación que, como efecto pragmático, logra reducir considerablemente una realidad problemática, tipificando, prejuiciando, lo que la convierte en una sólida novela, pero no necesariamente en una novela propositiva sobre la realidad de la favela. Por otra parte, su anacrónica visión del realismo distancia casi automáticamente a casi cualquier lector crítico de 'lo real', si es que esto aún es posible en el discurso literario; la autenticidad discursiva se pierde, y nos propone una historia con la que el lector se puede sentir 'familiarizado' (de ahí que como novela sea muy efectiva y entretenida), y es en ese sentido 
que su posible crítica explícita tiende a desvanecerse en pos de la historia, el suspenso, el confortable lugar común. Lo que buscan los nuevos modos críticos del realismo, según lo entiendo, es precisamente lo contrario: dislocar los juicios prestablecidos del lector (tanto estéticos como morales), en una lectura que provoque, en el más amplio sentido: que sea una provocación, y que a la vez provoque (genere) una reacción. El discurso es precisamente el lugar donde debe generarse esta tensión. En este sentido, en ningún caso podría pensarse en Cidade de Deus como una mirada 'neutra' sobre esa realidad; ningún discurso podría. La privilegiada condición de Paulo Lins como testigo/investigador/autor no asegura tampoco una mirada 'de autoridad' sobre dicha realidad. Y es precisamente esa mirada de autoridad la que, pienso, el texto de Lins, en tanto construcción discursiva, pretende evitar, a la vez que hace explícita su intención de provocar, en el sentido que anteriormente referí. Esta provocación (este intento de poner en tensión las estructuras tradicionales del realismo, esta apelación implícita al lector, este desmantelamiento del discurso total y totalizador moderno) refleja el discurso ideológico que configura la novela de Lins, opuesta en casi todo sentido a la de Melo, aunque no por ello 'inocente' (¿no se presenta la violencia como la única respuesta posible?, ¿no glorifica a algunos de los bandidos?, ¿no termina por estigmatizar el espacio que representa?).

La novela de Lins puede tener muchas deficiencias, pero es evidente que como construcción narrativa presenta una alternativa opuesta a Inferno. Melo opta por la mirada totalizadora y moral, que se evidencia en su conservadurismo estético. El discurso de Lins es todo lo contrario. Si la realidad es difícil de asir, contradictoria, aparentemente falta de una lógica profunda, entonces el relato debe dar cuenta de esa realidad, no a través de la explicación sino de la forma: la fragmentariedad, el orden estructuradamente caótico, las pequeñas historias y subjetividades inconclusas que vagamente forman parte de un todo: la indecibilidad de lo real se manifiesta en el propio discurso. Y es ese giro, pese a la voz 'poética' que a veces irrumpe, o incluso en cierto sentido por esa voz, el que hace de esta novela un relato si no más real, al menos más auténtico, más comprometido con la realidad que representa en su aparente desidia. El mundo de Lins es también un 'infierno', pero no necesita decirlo. Y entonces la novela es documento, y lo enfatiza (contradictoriamente esto ha llevado a una lectura muy empobrecedora del texto); la novela de Melo no. Es también, en ese mismo sentido, un relato parcialmente 
autobiográfico, o al menos testimonial (con toda la carga de realidad y evidente subjetividad que el testimonio implica). Y es, finalmente, una ficción novelesca, que es lo que sí comparte con Inferno, sólo que Cidade es un texto sumamente consciente de su materialidad discursiva, de su peso estético, de su ser antes que nada literatura, que es lo que la novela de Melo quiere disfrazar de objetividad.

\section{Referências}

AUERBACH, Erich (2001). Mimesis. La representación de la realidad en la literatura occidental. Distrito Federal, México: Fondo de Cultura Económica.

CRUZ, Adelcio de Souza (2010). Três visões literárias da violência: Clarice Lispector, Conceição Evaristo e Patrícia Melo. In: FAZENDO GÊNERO, 9, Florianópolis, 23 a 26 ago. 2010. Anais... Florianópolis: UFSC, 2010. p. 1-10.

EAGLETON, Terry (1997). Ideología: una introducción. Barcelona: Paidós.

GENETTE, Gérard (1989). Figuras III. Barcelona: Lumen.

LINS, Paulo (1997). Cidade de Deus. São Paulo: Companhia das Letras.

LYOTARD, Jean-François. La condición postmoderna: informe sobre el saber. Madrid: Cátedra, 2012.

LUKÁCS, Georg (1965). Ensayos sobre el Realismo. Buenos Aires: Siglo XX.

MARGATO, Izabel; GOMES, Renato Cordeiro (2012). Novos Realismos. Belo Horizonte: Editora UFMG.

MELO, Patrícia (2000). Inferno. São Paulo: Companhia das Letras.

NITSCHACK, Horst (2005). Cidade de Deus de Paulo Lins y La virgen de los sicarios de Fernando Vallejo: el adolescente como sujeto absoluto. In: CARRERAS, Sandra; POTTHAST, Barbara (Eds.). Entre la familia, la sociedad y el Estado. Niños y jóvenes en América Latina (siglos XIX- XX). Madrid: Iberoamericana; Frankfurt am Main: Vervuert. p. 311-331.

SCHOLLHAMMER, Karl Erik (2001). From the Malandro (Rogue) to the Traficante (Drug Trafficker) - Two constellations of violence in Brazilian culture. Diálogos Latinoamericanos, Aarhus, n. 4, p. 37-46.

SCHOLLHAMMER, Karl Erik (2009). Ficção brasileira contemporânea. Rio de Janeiro: Civilização Brasileira. 
CENTRO DE ESTUDIOS DE TEORÍA Y CRÍTICA LITERARIA (2005). Boletin, Rosario, n. 12.

VAN DIJK, Teun A. (2008). Semántica del discurso e ideología. Discurso $\mathcal{E}$ Sociedad, Barcelona, v. 2, n. 1, p. 201-261.

ZOLIN, Lúcia (2006). Inferno, de Patrícia Melo: gênero e representação. Estudos de Literatura Brasileira Contemporânea, Brasília, n. 28, p. 71-86.

Recebido em janeiro de 2014.

Aprovado em agosto de 2014.

\section{resumo/abstract}

\section{Representación de la violencia y la marginalidad en el discurso de Cidade de Deus e Inferno}

Matías Rebolledo Dujisin

Este trabajo analiza dos reconocidas novelas brasileñas que abordan el problema de la violencia urbana y la marginalidad desde un estilo y perspectiva aparentemente similar: Cidade de Deus (1997) de Paulo Lins e Inferno (2000) de Patrícia Melo. Sin embargo, a partir de un análisis de estructuras intratextuales se evidencia que en su misma construcción verbal estos discursos sustentan una visión de mundo y una concepción ideológica radicalmente distintas, pese a su aparente afinidad. Siendo el tema de la violencia y la marginalidad uno de los temas más explotados y explorados en las últimas décadas, la comparación entre ambas novelas, como configuración poética de éste, demuestra la dificultad radical de dar una explicación y un sentido único a este fenómeno.

Palavras-chave: violencia, novela brasileña, Paulo Lins, Patrícia Melo.

\section{Violence and marginality representation in Cidade de Deus and Inferno's discourse}

Matías Rebolledo Dujisin

The present article analyses two major contemporary Brazilian novels that deal with the subject of urban violence and marginality, apparently from a similar point of view and writing style, Paulo Lins' Cidade de Deus (1997) and Patrícia Melo's Inferno (2000). The analysis of the internal structures of this texts shows, 
nevertheless, that both discursive constructions uphold opposite world views and ideological conceptions, despite their superficial affinity. Violence and marginality, in fact, are probably the most exploited and discussed subjects in the last few decades in Brazil, so the comparison between the poetical construction in both novels reveals that it is almost impossible to maintain an univocal sense and explanation of this contemporary condition.

Palavras-chave: narrative structures, brazilian literature, representation, marginality. 